\title{
Experimental investigations and optimization of forming force in incremental sheet forming
}

\author{
AJAY KUMAR* and VISHAL GULATI \\ Department of Mechanical Engineering, Guru Jambheshwar University of Science and Technology, Hisar, \\ Haryana 125001, India \\ e-mail: ajay.kumar30886@gmail.com
}

MS received 28 November 2017; revised 12 April 2018; accepted 13 April 2018; published online 14 August 2018

\begin{abstract}
Incremental sheet forming process has been proved to be quiet suitable and economical for job and batch type production, which exempts expensive and complex tooling for sheet forming. Investigation of forming forces becomes important for selecting the appropriate hardware and optimal process parameters in order to assure perfection and precision of process. Moreover, lack of available knowledge regarding the process parameters makes the process limited for industrial applications. This research paper aims at finding out effects of different input factors on forming forces in single-point incremental forming (SPIF) process. For operation sustainability and hardware safety, it becomes critical to optimize forming forces for a given set of factors to form a particular shape. In this study, optimization of input factors has been performed to produce conical frustums with helical tool path using Taguchi analysis as design of experiment (DOE) and analysis of variance (ANOVA). The optimal experimental conditions for forming forces have been calculated as sheet thickness $(0.8 \mathrm{~mm})$, step size $(0.2 \mathrm{~mm})$, tool diameter $(7.52 \mathrm{~mm})$, tool shape (hemispherical), spindle speed (1000 rpm), feed rate $(1000 \mathrm{~mm} / \mathrm{min})$ and wall angle $\left(50^{\circ}\right)$. Effects of tool shape and viscosity of lubricants have also been investigated. An intensive understanding of the mechanism of forming forces has been presented, which shows that force trend after peak values depends upon instant input factors that can be categorized as a safe, severe and crucial set of parameters.
\end{abstract}

Keywords. SPIF; optimization; forming force; ANOVA; process parameters.

\section{Introduction}

Traditional sheet metal forming processes need dedicated and highly specialized equipment such as forming presses, dies and punches, so these processes are expensive and time-consuming in producing sheet metal parts [1]. Hence, manufacturing of small batch size products and prototypes is not very economical using conventional forming processes in sheet metal forming. Multi-variety components in small batches can be manufactured at low cost with singlepoint incremental forming (SPIF) technology, which prevents limitations of traditional sheet metal forming processes [2]. SPIF is more suitable for the batch type and prototype production due to economical tooling cost, shorter lead time and ability to form nonsymmetrical geometries without using expensive dies for manufacturing complex components of sheet metal [3,4]. SPIF finds its application mainly in the medical sector, aerospace and automotive industry. This is a truly die-less process in which forming tool is generally programmed to move along a CNC-controlled definite path to form a predetermined

*For correspondence shape by local deformation layer by layer as shown in figure 1. As the sheet is squeezed locally by the tool, forming forces become very important regarding fracture mechanism and precision of the formed part. Forming force produces stresses and strain in the sheet depending upon part shape, which further determines the structural integrity of the final component [5]. Also, it is important to estimate maximum forming force to ensure the safe utilization of forming hardware.

Different researchers have focused on studying forming forces developed during the process and impact of various process parameters. Forming path of the traveling tool is most crucial for the successful forming of the components. In profile tool path, the tool moves in a single plane, reaches its initial point and then it takes a step depth in the vertically downward direction (figure $2 \mathrm{a}$ ). This process continues till the complete shape is formed. In case of the helical tool path, the punch moves along the periphery, maintaining the predetermined gradual helix along the vertical direction as shown in figure $2 \mathrm{~b}$. Blaga and Oleksik [6] and Thibaud et al [7] studied effects of constant Z-level (profile) and helical tool path and revealed that helical tool path formed geometry successfully, whereas, constant Z- 


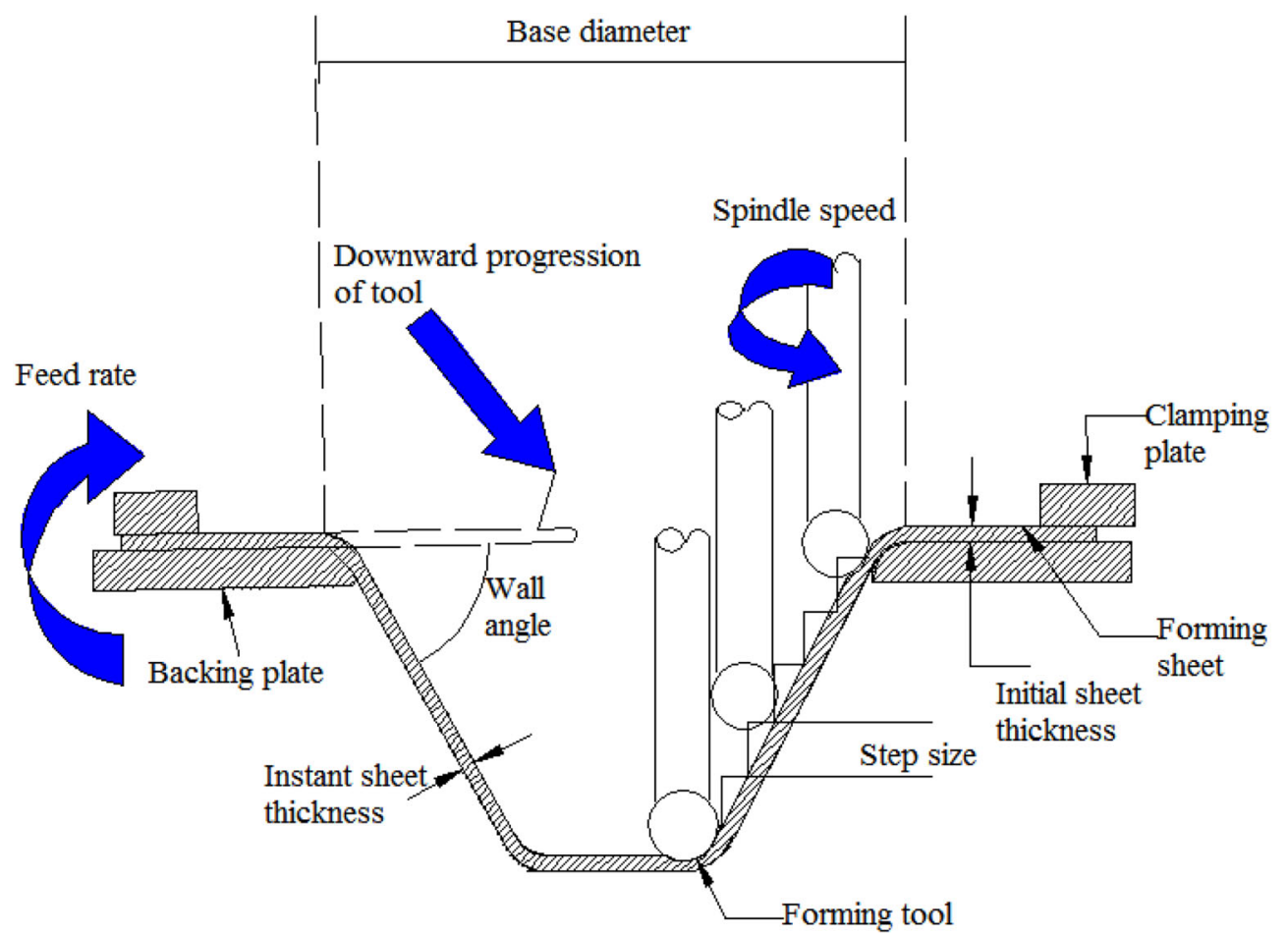

Figure 1. Single-point incremental forming.

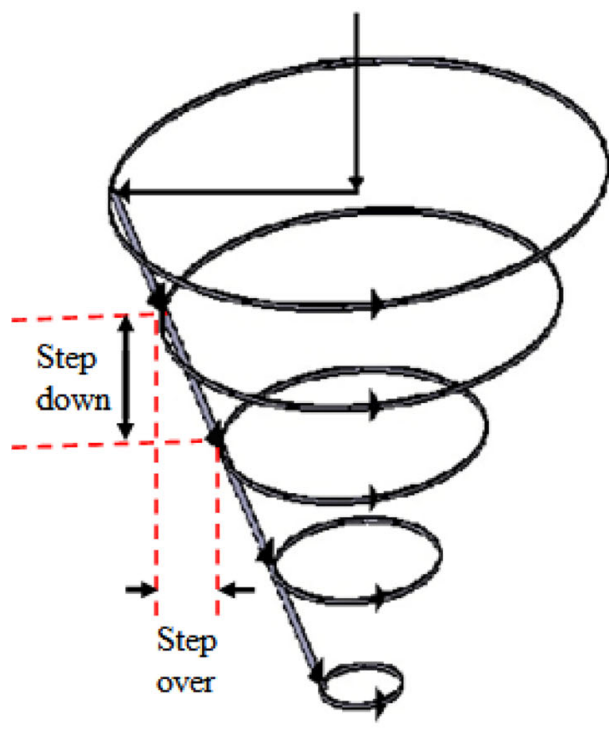

(a)

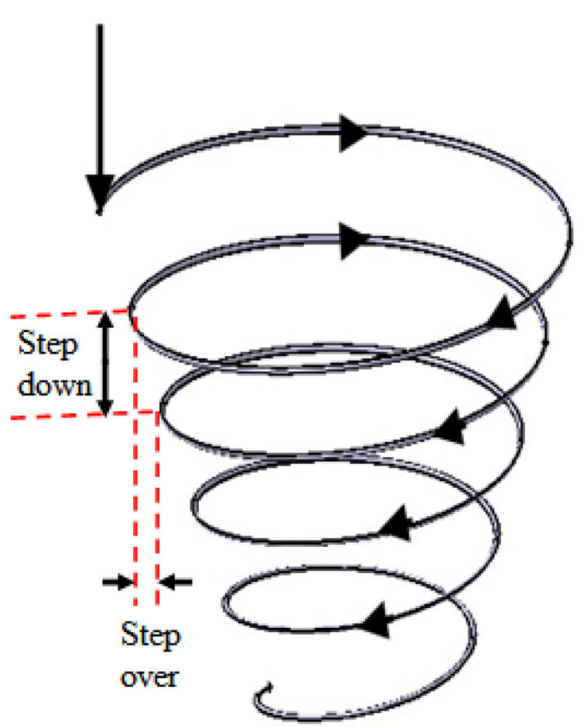

(b)

Figure 2. Tool paths for truncated cone: (a) profile tool path and (b) helical tool path.

level tool path resulted in cracking sheet before the depth as obtained by helical tool path. Arfa et al [8] also studied the impact of profile and helical tool path in order to produce truncated cone shape on AA3003-O sheets by experimental as well as simulation trails using ABAQUS software. For helical tool path, the load exerted by tool was more stable and there was no unexpected force drop in the vertical direction. $\mathrm{Li}$ et al [9] studied the effects of hemispherical headed tool and ball tool in a groove test with SPIF on AA7075-O sheets experimentally and compared it 
to the results obtained by FEM analysis using LS-DYNA software. Results showed that there was a sharp increase at the end of each travel. Bagudanch et al [10] determined influence of different tool diameters on the maximum forming force in SPIF on PVC sheets. Petek et al [11] observed that the maximum force $(\mathrm{Fz})$ in the vertical direction with $16 \mathrm{~mm}$ tool diameter was approximately $15 \%$ more than that obtained with $10 \mathrm{~mm}$ tool diameter.

Duflou et al [12] investigated the influence of vertical steps on AA3103-O sheets and found that forming forces rise with the rise in step size. Bagudanch et al [10] determined influence of spindle speed on forming forces during SPIF on PVC sheets to form pyramidal frusta with circular generatrix. The forming forces were found to decrease with increase in spindle speed. Centeno et al [13] analysed the influence of different spindle speeds (free, $1000 \mathrm{rpm}$ ) in SPIF on axial forming forces on AISI304 stainless steel sheets and found that the effect of the spindle speed was significant, especially for the case of a forming tool of 20 $\mathrm{mm}$ diameter. Liu et al [14] studied the influence of different wall angles $\left(60^{\circ}, 65^{\circ}\right.$ and $\left.70^{\circ}\right)$ and tool paths (helical and profile) on AA7075-O sheets and found that as the wall angle increases, the resultant peak force also increases in the initial stage.

Proper use of lubrication greatly increases tool life, removes waste material and reduces forming forces by reducing friction and wear at the tool-sheet interface. Azevedo et al [15] investigated influences of different lubricants using SPIF for steel (DP780) and aluminium (AA1050-T4) sheets. Petek et al [11] investigated effects of SYLAC 80-85 lubricant combined with different spindle speeds on the vertical component of forming force produced during SPIF on DC05 steel sheets. Understanding of mechanism of forming forces in incremental sheet forming has become an interesting approach. Ambrogio et al [16] proposed a methodology to detect failure with forming force in SPIF on AA1050-O aluminium sheets and found that bending mechanism is responsible in the initial stage in which force increases gradually up to a high value, whereas force trend shows a quite complex behaviour in which stretching seems to be significant after the peak up to failure of the sheet due to material thinning and strain hardening. The same trend was monitored by Filice et al [17], who revealed that force trend strongly depends on the tool diameter, step depth and wall angle. Moreover, the force peaks and force gradient after the peaks are strongly related to the material failure.

Literature reports that some process parameters like punch diameter, tool rotation, wall angle, sheet thickness, step size, etc., influence the forming forces significantly. Moreover, there are certain input factors like the viscosity of lubricating oil and tool shape that have not been investigated to assess process capabilities and to optimize the process. The viscosity of the lubricants is crucial and maintains separation of tool and sheet at contact zone [18].
Effects of each process parameters are required to know the forming forces by a process engineer for implementation of the process on the industrial scale. SPIF suitability can be enhanced on the industrial scale only when significant guidelines are highlighted regarding a relation between input parameters and required forming forces. Hence, investigation and optimization of process parameters are very important in the field of SPIF. Regarding this, it is customary to conduct an experimental study to know effects of process parameters on forming forces and to find optimum conditions of the process for development of accurate process models.

Different researchers have focused on certain materials like AA3003-O [8], AA7075-O [9], PVC [10], DC05 [11] and AA3103-O [12] steel sheets in order to find the impact of different process parameters on forming forces. It has also been found that aluminium alloy AA2024-O has not been investigated to check effects of process parameters, which finds application in aerospace sectors due to suitable mechanical and physical properties of aluminium alloys, like low density and reduced weight without compromising with the strength of the material, better toughness and corrosion resistance. Moreover, the mechanical property of the formed component (AA2024-O) can be enhanced by artificial aging. This alloy is known for its inherent property of damage control and able to retain its strength over a wide temperature range and is used for fuselage parts and wings of aero-plane [19]. Most of the manufacturing processes have technological complications and different controllable and uncontrollable factors; hence, proper design of experiment (DOE) can simultaneously determine the capacity of input parameters to influence the selected responses [20]. Taguchi method can be used efficiently for design and analysis of experiments and quality of the process can be optimized [21].

This work points towards systematic investigation by varying process parameters on AA2024-O sheets of thicknesses 0.8 and $1.0 \mathrm{~mm}$ using Taguchi as DOE and optimizing technique so that minimum forming force can be achieved. Some input factors like tool shape and the viscosity of lubricant are also taken into account, which have not been included in the investigation on optimization of forming forces of formed parts in literature to the best of author's knowledge. Effects of eight input factors, i.e., tool rotation, sheet thickness, tool diameter, wall angle, step size, feed rate, tool shape and lubrication, are investigated to find required forming force in the axial direction of the forming tool. Flat end tools with corner radius and hemispherical tools of different diameters have been investigated on AA2024-O sheets in order to study tool shape effects. A series of experiments have been performed using DOE based on Taguchi method in SPIF process. An analysis of variance (ANOVA) has also been performed to set optimal parameters setting in order to find the optimal forming force. Effects of tool shape, tool diameter, the viscosity of lubricant and spindle speed are also 
Table 1. Chemical compositions of aluminium alloys used

Chemical composition (wt\%)

\begin{tabular}{lccccccccc}
\hline AA 2024-O & $\mathrm{Al}$ & $\mathrm{Cr}$ & $\mathrm{Cu}$ & $\mathrm{Fe}$ & $\mathrm{Mg}$ & $\mathrm{Mn}$ & $\mathrm{Si}$ & $\mathrm{Ti}$ & $\mathrm{Zn}$ \\
& 91.50 & 0.10 & 4.60 & 0.30 & 1.70 & 0.80 & 0.50 & 0.10 & 0.20 \\
AA 6063-O & Balance & $0.04-0.35$ & $0.15-0.40$ & - & $0.8-1.2$ & 0.15 & $0.4-0.8$ & 0.15 & 0.25 \\
\hline
\end{tabular}

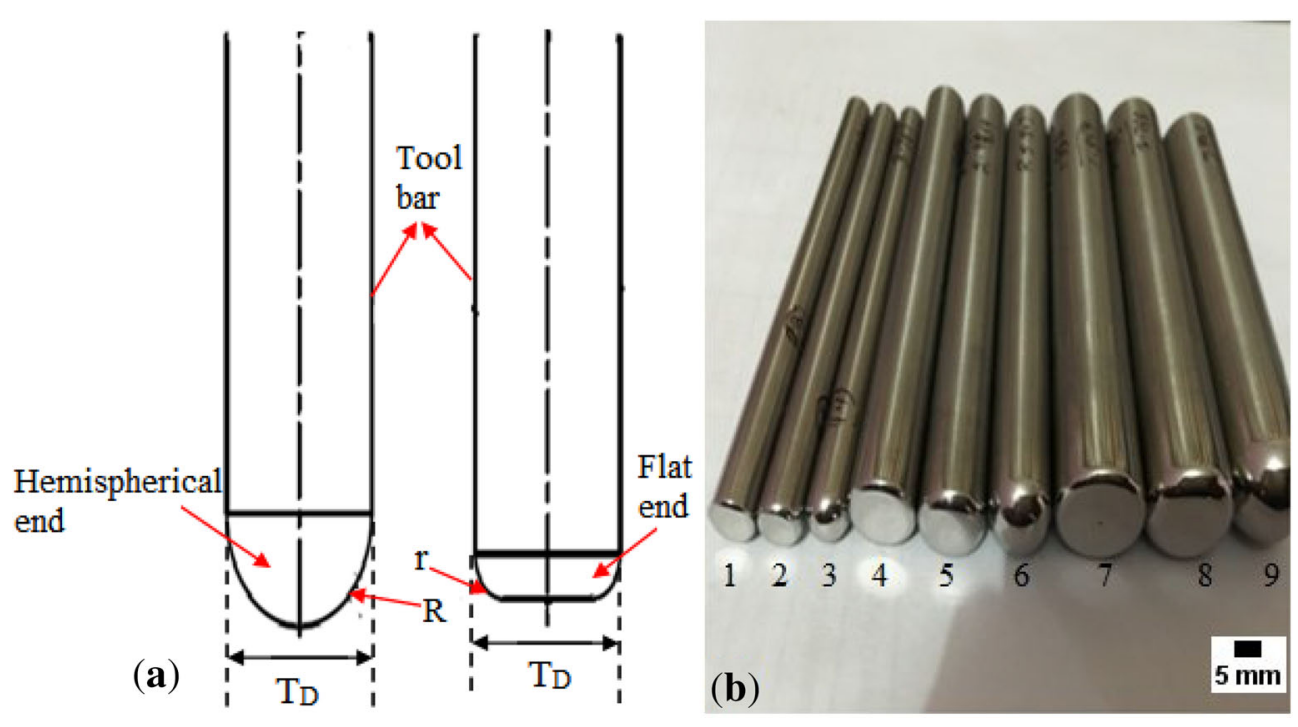

Figure 3. Forming tools: (a) geometry and (b) pictorial representation.

investigated as a trial set of experiments on AA6063-O aluminium sheets of thickness $1.2 \mathrm{~mm}$.

\section{Material and methods}

\subsection{Experimental equipment}

SPIF tests were conducted on aluminium alloys sheets of size $250 \times 250 \mathrm{~mm}^{2}$. Table 1 shows the chemical composition of alloys used. An optical emission spectrometer (Foundry Master, Oxford Instruments, Uedem, Germany) has been used to measure the chemical composition of the alloys taken into account. It is also crucial to select material and geometry (shape and size) of the forming tool for producing different work-piece shapes. In this work, HSS tools have been used to investigate effects of tool diameters and forming end radii on forming forces. The geometrical details of forming tools are shown in figure 3 and table 2 . Hemispherical-end and flat-end tools having lower and higher corner radius were formed and hardened to 64 HRC and then tempered before finishing the process. End radii of the tools were measured using a contour measuring system Contracer CV-2100 (accuracy $= \pm(2.5+10.1 H \mid) \mu \mathrm{m}$, where $H$ is displacement from mid-range position (mm), measurement range of detector $=50 \mathrm{~mm}$, resolution $=$ $0.1 \mu \mathrm{m})$
Table 2. Geometrical details of forming tools.

\begin{tabular}{lcccc}
\hline & $\begin{array}{c}\text { Tool } \\
\text { diameter } \\
T_{\mathrm{D}}\end{array}$ & $\begin{array}{c}\text { Side radius } \\
\text { of flat-end } \\
\text { tool } \\
\text { Tool }\end{array}$ & $\begin{array}{c}\text { Radius of } \\
\text { hemispherical- } \\
\text { end tool }\end{array}$ & \\
no. & $(\mathrm{mm})$ & $r(\mathrm{~mm})$ & $R(\mathrm{~mm})$ & Symbol \\
\hline 1 & 7.52 & 1.40 & - & Flat end\#1 \\
2 & & 2.00 & - & Flat end\#2 \\
3 & & - & 3.76 & Hemispherical \\
4 & 11.60 & 1.98 & - & Flat end\#1 \\
5 & & 2.85 & - & Flat end\#2 \\
6 & & - & 5.80 & Hemispherical \\
7 & 15.66 & 1.85 & - & Flat end\#1 \\
8 & & 3.76 & - & Flat end\#2 \\
9 & & - & 7.83 & Hemispherical \\
\hline
\end{tabular}

A CNC milling machine (table size $1200 \times 550 \mathrm{~mm}^{2}$, travel $x$-axis $1050 \mathrm{~mm}, y$-axis $610 \mathrm{~mm}, z$-axis $510 \mathrm{~mm}$, load capacity $1000 \mathrm{~kg}$ ) with a Siemens controller has been used to perform experiments (figure $4 \mathrm{a}$ ). CAD models of the truncated cone with different wall angles $\left(50^{\circ}, 60^{\circ}, 68^{\circ}\right)$ were designed by UG-NX software and then imported to DEL-CAM to prepare the part program, which was directly sent to the CNC controller to form the required shape. Figure $4 \mathrm{~b}$ presents the geometry of conical frustum to be formed. Truncated cones of $120 \mathrm{~mm}$ upper diameter and 70 

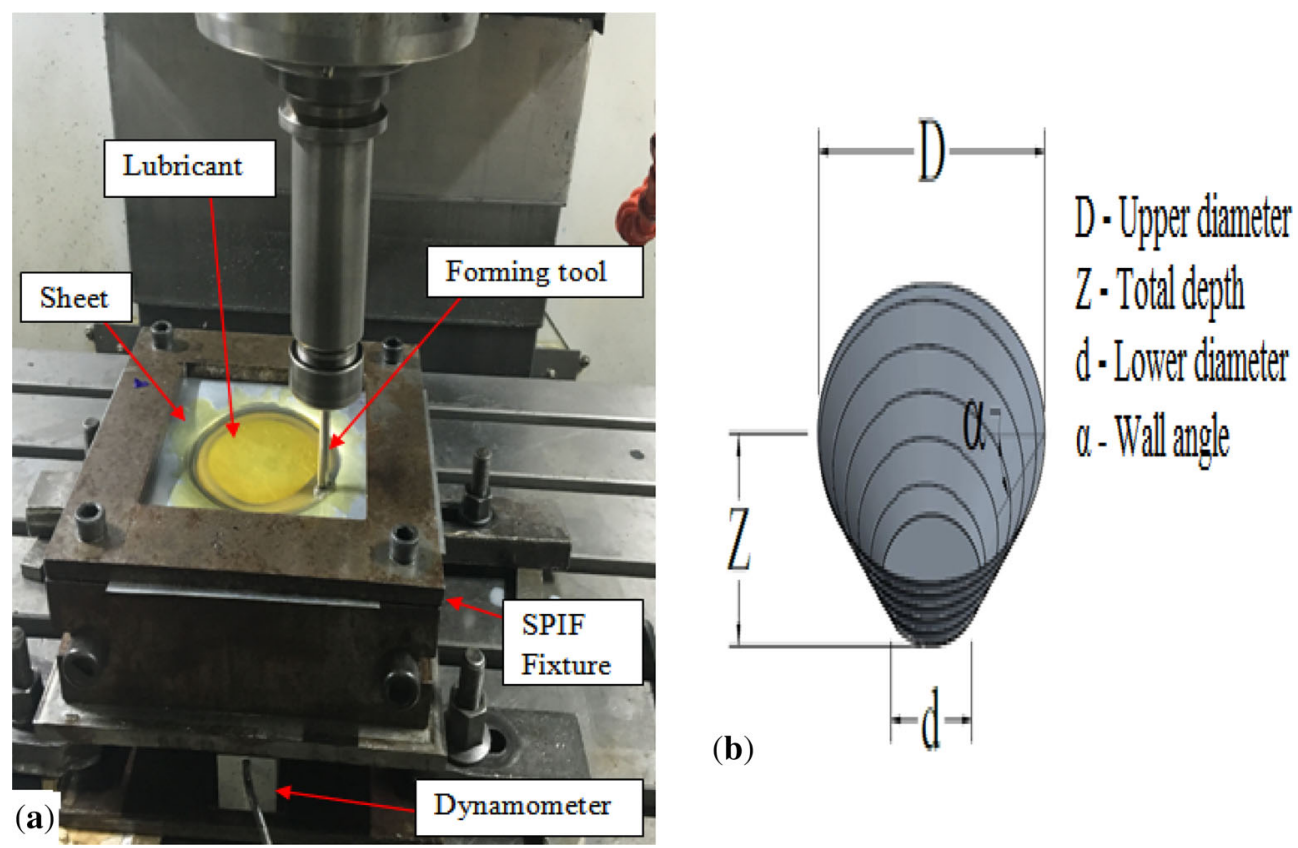

Figure 4. (a) Experimental set-up and (b) geometry of conical frustum.

Table 3. Physical properties of selected lubricants.

\begin{tabular}{lccc}
\hline Castrol lubricant & $\begin{array}{c}\text { Alpha } \\
\text { SP 68 }\end{array}$ & $\begin{array}{c}\text { Alpha } \\
\text { SP 150 }\end{array}$ & $\begin{array}{c}\text { Alpha } \\
\text { SP 320 }\end{array}$ \\
\hline $\begin{array}{l}\text { ISO viscosity grade } \\
\text { Kinematic viscosity }\end{array}$ & 68 & 150 & 320 \\
$@ 40^{\circ} \mathrm{C}(\mathrm{cSt})$ & 68 & 150 & 320 \\
@ $100^{\circ} \mathrm{C}(\mathrm{cSt})$ & 8.53 & 14.5 & 24.0 \\
Relative density @ 20 ${ }^{\circ} \mathrm{C}$ & 0.885 & 0.890 & 0.900 \\
$\begin{array}{l}\text { Pour point }\left({ }^{\circ} \mathrm{C}\right) \\
\text { Load carrying capacity according } \\
\text { to Brugger }\left(\mathrm{N} / \mathrm{mm}^{2}\right)\end{array}$ & -21 & -21 & -21 \\
\hline
\end{tabular}

$\mathrm{mm}$ vertical depth were designed to be formed. Lower diameters of the cone were controlled by wall angles. A helical tool path (figure $2 \mathrm{~b}$ ) has been used as it produces minimum forming forces and better quality of the part. In helical tool path, the tool moves both in the inward radial direction $(\Delta x)$ to take the step over, as well as in vertical direction $(\Delta z)$ to push the sheet towards the depth of cone. Three different types of Castrol oils having different viscosities are studied on forming forces. These oils have good water resistance, thermal stability, rust and corrosion resistance, oxidation protective nature and de-emulsification characteristics. The properties of the lubricants are shown in table 3. A strain-gauge-based force dynamometer was placed below the fixture in which sheet was clamped in order to measure forming forces required to form the cone shape. A Nictech-3X-MTD-350/700-500 data logger system has been used for recording force values provided by dynamometer for given time ranges. The data logger system is also equipped with Microscada software in order to facilitate the processed force values in a PC-based environment.

In the first set of experiments, effects of tool shape, tool diameter, viscosity of lubricant and spindle speed are studied on AA6063-O aluminium sheets of thickness 1.2 $\mathrm{mm}$ having the following other factors constant, i.e., feed rate $1000 \mathrm{~mm} / \mathrm{min}$, wall angle $60^{\circ}$ and step size $0.5 \mathrm{~mm}$, in order to form a truncated cone shape having upper diameter $120 \mathrm{~mm}$ with helical tool path, and results are shown in table 4.

\subsection{Methodology for process variables optimization}

DOE organized by Taguchi method permits performing certain pairs of combinations rather than performing all possible tests and suggests most affecting factors with least set of experiments [22]. In the current study, eight input parameters are also analysed and varied together first time without considering the interaction effects to optimize the process to find minimum forming forces in the axial direction of forming tool on AA2024-O sheets. Among these eight parameters, sheet thickness was at two levels, whereas tool diameter, wall angle, step size, feed rate, tool shape, lubrication and spindle speed were at three levels as shown in table 5. Hence the total number of independent experimental comparisons is calculated as $[2-1]+[7 \times$ $(3-1)]+1=16$, which is also known as degrees of freedom (DOF). Now, an orthogonal array (OA) has been designed 
Table 4. Input factors and forming force results.

\begin{tabular}{lccccc}
\hline Trial no. & Tool diameter $(\mathrm{mm})$ & Tool shape & Kinematic viscosity $(\mathrm{cSt})$ & Spindle speed (rpm) & Maximum axial force (N) \\
\hline 1 & 7.52 & Flat end\#1 & 68 & 1000 & 562 \\
2 & 7.52 & Flat end\#2 & 68 & 1000 & 536 \\
3 & 7.52 & Hemispherical & 68 & 1000 & 511 \\
4 & 7.52 & Hemispherical & 320 & 1000 & 513 \\
5 & 7.52 & Hemispherical & 320 & 1000 & 539 \\
6 & 11.60 & Flat end\#1 & 68 & 1000 & 634 \\
7 & 11.60 & Flat end\#2 & 68 & 1000 & 580 \\
8 & 11.60 & Hemispherical & 68 & 1000 & 544 \\
9 & 11.60 & Hemispherical & 320 & Free & 547 \\
10 & 11.60 & Hemispherical & 320 & 1000 & 576 \\
11 & 15.66 & Flat end\#1 & 68 & 1000 & 687 \\
12 & 15.66 & Flat end\#2 & 68 & 1000 & 651 \\
13 & 15.66 & Hemispherical & 68 & 1000 & 619 \\
14 & 15.66 & Hemispherical & 320 & Free & 622 \\
15 & 15.66 & Hemispherical & 320 & 649 \\
\hline
\end{tabular}

Table 5. Input parameters with different levels.

\begin{tabular}{|c|c|c|c|c|c|c|c|}
\hline \multirow[b]{3}{*}{ Symbol } & \multirow[b]{3}{*}{ Input parameters } & \multicolumn{6}{|c|}{ Levels of input factors } \\
\hline & & \multicolumn{3}{|c|}{ Original values } & \multicolumn{3}{|c|}{ Coded values } \\
\hline & & Level 1 & Level 2 & Level 3 & L1 & L2 & L3 \\
\hline$A$ & Sheet thickness (mm) & 0.8 & 1.0 & - & 1 & 2 & - \\
\hline$B$ & Tool diameter $(\mathrm{mm})$ & 7.52 & 11.60 & 15.66 & 1 & 2 & 3 \\
\hline$C$ & Step size $(\mathrm{mm})$ & 0.2 & 0.5 & 0.8 & 1 & 2 & 3 \\
\hline$D$ & Wall angle (deg) & 50 & 60 & 68 & 1 & 2 & 3 \\
\hline$E$ & Feed rate $(\mathrm{mm} / \mathrm{min})$ & 1000 & 1500 & 2000 & 1 & 2 & 3 \\
\hline$F$ & Tool shape & Flatend\#r1 & Flatend\#r2 & Hemispherical & 1 & 2 & 3 \\
\hline$G$ & Viscosity of forming oil (cSt) & 68 & 150 & 320 & 1 & 2 & 3 \\
\hline$H$ & Spindle speed (rpm) & Free & 500 & 1000 & 1 & 2 & 3 \\
\hline
\end{tabular}

to study the impact of input parameters of the process. According to the Taguchi method, total DOF of the selected array should be higher than required DOF of the process, which is 16 in this case. Hence, columns are provided to all input parameters for a chosen mixed level OA L18 $\left(2^{1} \times 3^{7}\right)$ and shown in table 6 .

\section{Results and discussion}

\subsection{Effects of preliminary investigation}

Preliminary experiments were performed to represent influences of tool shape, tool diameter, viscosity of lubricant and spindle speed. The maximum peak forces in the axial direction are represented and analysed in table 4 and figure 5 .

It is clear from figure 5 that an increase in punch diameter results in increasing forming forces in the axial direction due to greater contact zone at the tool-sheet interface and more material is formed at that instant. This could become a limiting factor for hardware used for forming operation and should be avoided. Forming time can be easily reduced by using greater tool radius by employing larger step sizes without compromising the surface integrity of formed parts [23]. The shape of the tool has also been proved to be a significant factor. As we go for hemispherical shape from flat end tool having low side radius through flat end tool with larger side radius, maximum forming forces were found to be decreased. A similar trend has been observed when spindle speed was increased from 'free to rotate' condition of the tool. This is due to the fact that increased friction rises temperature at contact zone, which improves the ductility of the material. Influence of viscosity of lubricants has been noticed negligible on forming forces. Components have been successfully formed without fracture and shown in figure 6.

Axial peak forces decreased approximately 9.07\%, $14.20 \%$ and $9.90 \%$ for $7.58,11.60$ and $15.66 \mathrm{~mm}$ tool diameters, respectively, when hemispherical end tools were used in place of flat end tools having lower corner radius (Flatend\#1). Similarly, axial peak forces were found to decrease $18.20 \%, 17.66 \%$ and $17.42 \%$ for Flatend\#1, Flatend\#2 and hemispherical shape, respectively, when tool diameter was reduced from 15.66 to $7.52 \mathrm{~mm}$. Forming 
Table 6. Experimental layout and the response variables using L18 OA.

\begin{tabular}{|c|c|c|c|c|c|c|c|c|c|c|c|c|c|}
\hline \multirow[b]{2}{*}{ Run } & \multicolumn{8}{|c|}{ Input parameters and their levels } & \multicolumn{3}{|c|}{ Response data } & \multirow[b]{2}{*}{$S / N$ ratio } & \multirow[b]{2}{*}{ Mean } \\
\hline & $A$ & $B$ & $C$ & $D$ & $E$ & $F$ & $G$ & $H$ & $\mathrm{Fz}_{\mathrm{a}}$ & $\mathrm{Fz}_{\mathrm{b}}$ & $\mathrm{Fz}_{\mathrm{c}}$ & & \\
\hline 1 & 1 & 1 & 1 & 1 & 1 & 1 & 1 & 1 & 338 & 332 & 329 & -50.4494 & 333.000 \\
\hline 2 & 1 & 1 & 2 & 2 & 2 & 2 & 2 & 2 & 420 & 424 & 427 & -52.5407 & 423.667 \\
\hline 3 & 1 & 1 & 3 & 3 & 3 & 3 & 3 & 3 & 395 & 399 & 402 & -52.0124 & 398.667 \\
\hline 4 & 1 & 2 & 1 & 1 & 2 & 2 & 3 & 3 & 297 & 294 & 299 & -49.4456 & 296.667 \\
\hline 5 & 1 & 2 & 2 & 2 & 3 & 3 & 1 & 1 & 496 & 492 & 499 & -53.9039 & 495.667 \\
\hline 6 & 1 & 2 & 3 & 3 & 1 & 1 & 2 & 2 & 548 & 552 & 547 & -54.7915 & 549.000 \\
\hline 7 & 1 & 3 & 1 & 2 & 1 & 3 & 2 & 3 & 298 & 303 & 301 & -49.5619 & 300.667 \\
\hline 8 & 1 & 3 & 2 & 3 & 2 & 1 & 3 & 1 & 639 & 645 & 647 & -56.1733 & 643.667 \\
\hline 9 & 1 & 3 & 3 & 1 & 3 & 2 & 1 & 2 & 568 & 565 & 567 & -55.0666 & 566.667 \\
\hline 10 & 2 & 1 & 1 & 3 & 3 & 2 & 2 & 1 & 572 & 576 & 574 & -55.1783 & 574.000 \\
\hline 11 & 2 & 1 & 2 & 1 & 1 & 3 & 3 & 2 & 501 & 496 & 495 & -53.9331 & 497.333 \\
\hline 12 & 2 & 1 & 3 & 2 & 2 & 1 & 1 & 3 & 784 & 788 & 790 & -57.9232 & 787.333 \\
\hline 13 & 2 & 2 & 1 & 2 & 3 & 1 & 3 & 2 & 640 & 648 & 643 & -56.1733 & 643.667 \\
\hline 14 & 2 & 2 & 2 & 3 & 1 & 2 & 1 & 3 & 593 & 600 & 601 & -55.5342 & 598.000 \\
\hline 15 & 2 & 2 & 3 & 1 & 2 & 3 & 2 & 1 & 789 & 786 & 781 & -57.9012 & 785.333 \\
\hline 16 & 2 & 3 & 1 & 3 & 2 & 3 & 1 & 2 & 628 & 632 & 636 & -56.0145 & 632.000 \\
\hline 17 & 2 & 3 & 2 & 1 & 3 & 1 & 2 & 3 & 772 & 778 & 774 & -57.7823 & 774.667 \\
\hline 18 & 2 & 3 & 3 & 2 & 1 & 2 & 3 & 1 & 920 & 917 & 912 & -59.2411 & 916.333 \\
\hline
\end{tabular}

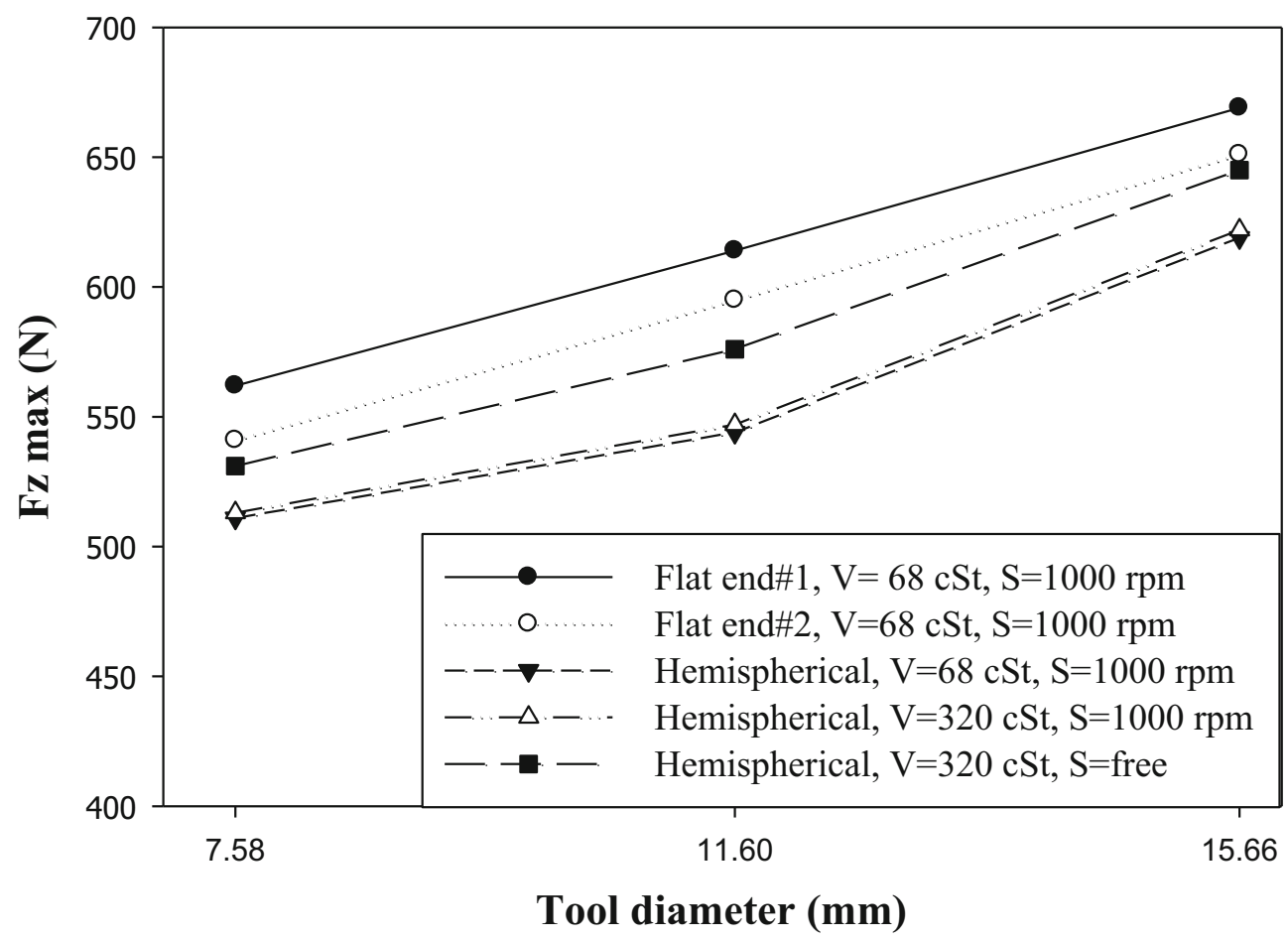

Figure 5. Evaluation of axial peak forces.

forces were found to increase $5.06 \%, 5.30 \%$ and $4.34 \%$ for $7.58,11.60$ and $15.66 \mathrm{~mm}$ tool diameters, respectively, when spindle speed was set to 'free to rotate' conditions as compared with spindle speed of $1000 \mathrm{rpm}$ with hemispherical end tools.

\subsection{Optimization of forming forces}

The influence of selected individual input factors of SPIF and their optimization have been studied on AA2024-O sheets in this section. The mean value and $S / N$ ratio of 

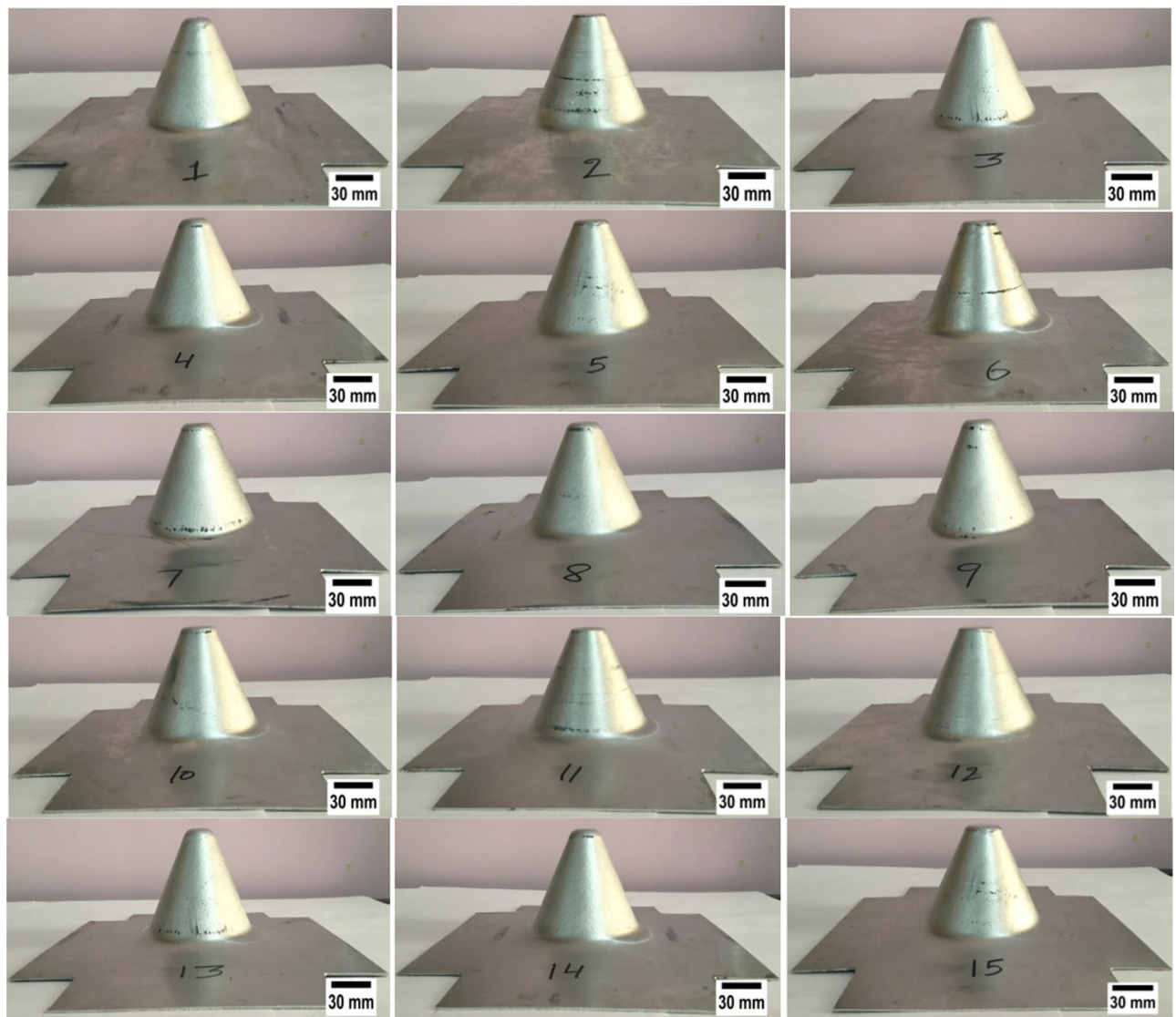

Figure 6. Pictorial representation of formed components (on AA6063-O sheets).

Table 7. Response table for mean (axial peak force).

\begin{tabular}{lcccccccc}
\hline Level & $A$ & $B$ & $C$ & $D$ & $E$ & $F$ & $G$ \\
\hline 1 & 445.3 & 502.3 & 463.3 & 542.3 & 532.4 & 621.9 & 568.8 \\
2 & 689.9 & 561.4 & 572.2 & 594.6 & 594.8 & 562.6 & 567.9 & 552.1 \\
3 & & 639.0 & 667.2 & 565.9 & 575.6 & 518.3 & 566.1 & 526.0 \\
Delta & 244.6 & 136.7 & 203.9 & 52.3 & 62.4 & 103.6 & 2.7 & 98.7 \\
Rank & 1 & 3 & 2 & 7 & 6 & 4 & 8 \\
\hline
\end{tabular}

axial peak forming force for every input factor with different levels have been determined (table 6). Later, response table (table 7) and main effects diagram (figure 7) have been employed for experimental data to show the influence of selected process variables on forces using Minitab-18 software. In order to determine significance and impact of different input factors on forming forces, ANOVA of measured values with $S / N$ values has also been executed (table 8 ). The optimal values of all input factors in terms of average forming forces were selected with the help of main effects diagrams and ANOVA table. Moreover, forming force is 'lower the better' type quality response; hence, lower value of forming force is accepted to be optimal.

\subsection{Response tables and response graphs}

Response table (table 7) has been employed for experimental data in order to calculate the most influencing factor on axial forces. Ranking of factors is dependent on delta values, which are given in the response table. Moreover, the difference between the maximum and the minimum value of every variable is the size of impact and is represented by delta value. Rank of the factors orders from most influencing factor to least influencing factor depending upon delta values. Moreover, response graph (figure 7) adds the response table analysis to assure optimal levels of input parameters on forming forces for means. Figure 7 and table 7 illustrate that mean value of measured peak forces 


\section{Main Effects Plot for Means}

\section{Data Means}

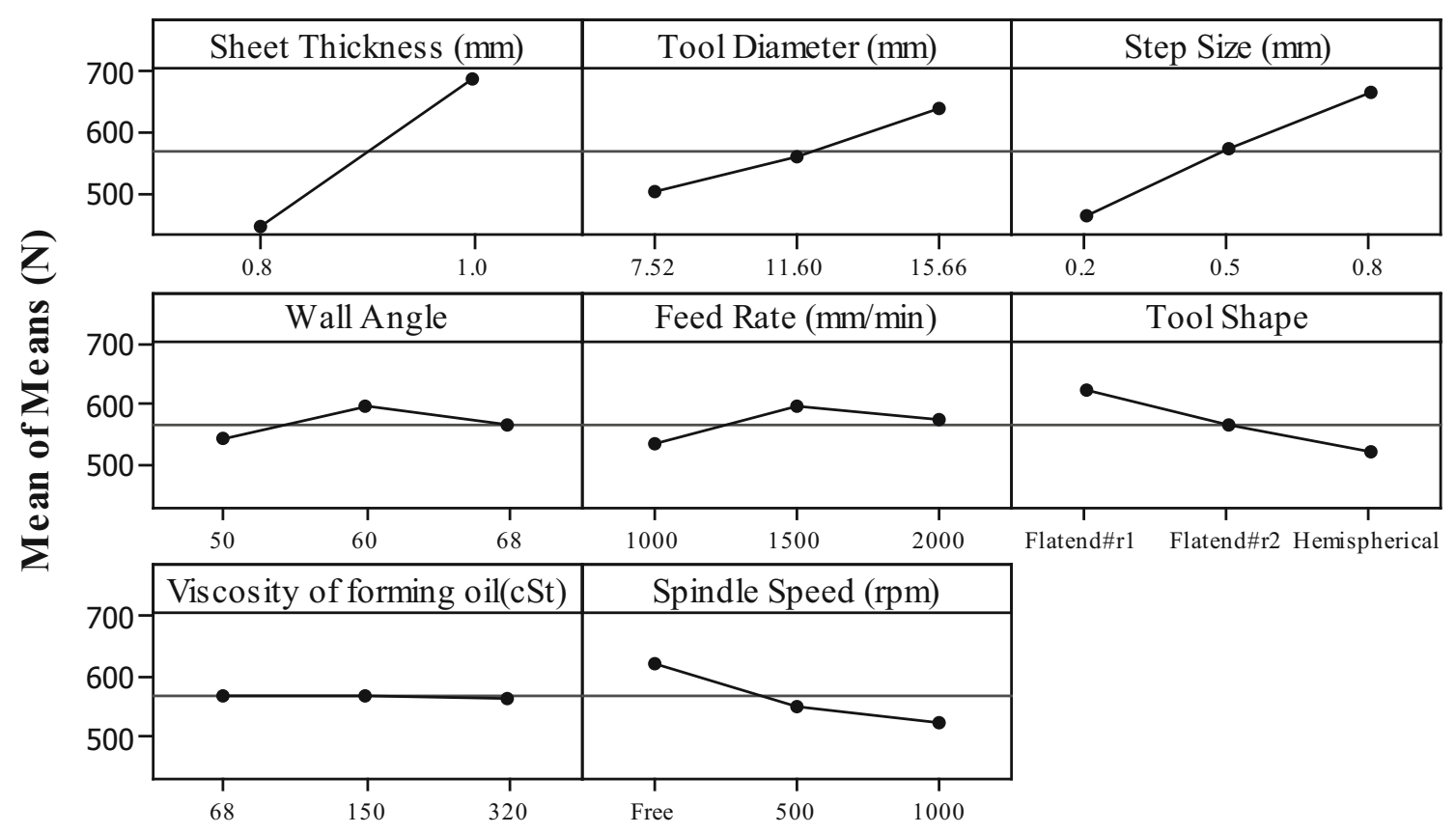

Figure 7. Main effects plot for means (axial peak forces).

is $567.57 \mathrm{~N}$ and minimum axial peak forces correspond to $A 1, B 1, C 1, D 1, E 1, F 3, G 1$ and $H 3$. It is also very interesting to define the most affecting process factor with the help of response table (table 8 ) by rank value in chronological ascending order, which is sheet thickness followed by the step size, tool diameter, tool shape, spindle speed, feed rate, wall angle and lubrication.

\subsection{ANOVA}

It is necessary to sort and eliminate non-significant parameters from significant ones to reduce process variability. ANOVA is very helpful in sorting significant variables from non-significant variables, using $P$-test as a cutoff criterion. At $95 \%$ confidence level, the factors having $P<0.05$ values are dominant for forming forces. Table 8 presents the ANOVA for axial peak force values in which higher value of $F$ represents higher significance of the factor. It is also clear from the ANOVA table (table 8) that all factors are significant for forming force except viscosity of lubricating oil as values of $P$ for significant factors are less than 0.05 for $95 \%$ confidence level.

\subsection{Effects of process variables}

It has been observed from figure 7 that forming force increases with increase in sheet thickness due to the fact

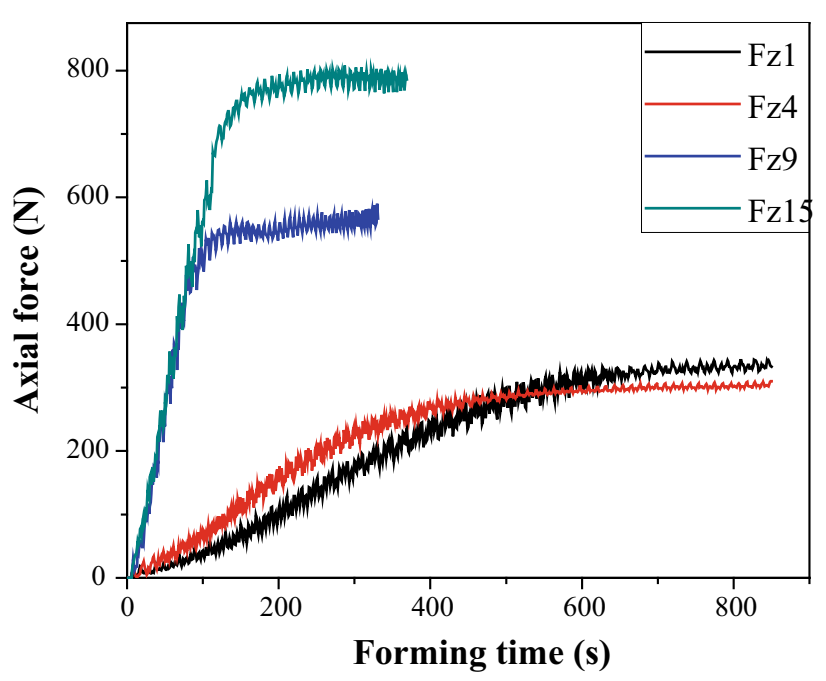

Figure 8. Force trend (steady) with safe parameters.

that more metal is subjected to forming per pass of the punch over the sheet, requiring higher forming force to form a specific shape. A similar trend has been observed in case of tool diameter and step size. Forces were found to increase with the increase in tool diameter because of increasing contact zone between punch and blank. At increased step size, material available for local deformation is increased at any instant, causing an increase in forming 
Table 8. Analysis of variance for axial peak forces, using adjusted SS.

\begin{tabular}{|c|c|c|c|c|c|c|}
\hline Source & DF & Adj SS & Adj MS & $F$-value & $P$-value & Contribution $(\%)$ \\
\hline$A$ & 1 & 807400 & 807400 & 6005.59 & 0.000 & 50.17 \\
\hline$B$ & 2 & 169133 & 84566 & 629.02 & 0.000 & 10.51 \\
\hline$C$ & 2 & 374706 & 187353 & 1393.56 & 0.000 & 23.28 \\
\hline$D$ & 2 & 24673 & 12337 & 91.76 & 0.000 & 1.53 \\
\hline E & 2 & 36751 & 18376 & 136.68 & 0.000 & 2.28 \\
\hline$F$ & 2 & 97297 & 48649 & 361.86 & 0.000 & 6.04 \\
\hline$G$ & 2 & 69 & 35 & 0.26 & 0.774 & 0.04 \\
\hline$H$ & 2 & 94118 & 47059 & 350.03 & 0.000 & 5.84 \\
\hline Error & 38 & 5109 & 134 & & & \\
\hline Lack-of-fit & 2 & 4680 & 2340 & 196.52 & 0.000 & \\
\hline Pure error & 36 & 429 & 12 & & & \\
\hline Total & 53 & 1609257 & & & & \\
\hline
\end{tabular}

$S=11.5949, R$-sq $=99.68 \%, R-\mathrm{sq}(\operatorname{adj})=99.56 \%, R$-sq $($ pred $)=99.36 \%$.

Table 9. Confirmatory results for axial forming forces.

\begin{tabular}{lcccc}
\hline Response & $\begin{array}{c}\text { Optimal set of } \\
\text { parameters }\end{array}$ & $\begin{array}{c}\text { Predicted optimal } \\
\text { value }(\mathrm{N})\end{array}$ & $\begin{array}{c}\text { Predicted confidence intervals at } \\
95 \% \text { confidence level }\end{array}$ & $\begin{array}{c}\text { Average peak force of three } \\
\text { confirmation experiments }(\mathrm{N})\end{array}$ \\
\hline $\begin{array}{c}\text { Forming } \\
\text { force }\end{array}$ & $\begin{array}{c}A 1, B 1, C 1, D 1, E 1, \\
F 3, G 1, H 3\end{array}$ & 124.48 & $105.88 \leq \mu_{\mathrm{FF}} \leq 143.08$ & 135 \\
\hline
\end{tabular}

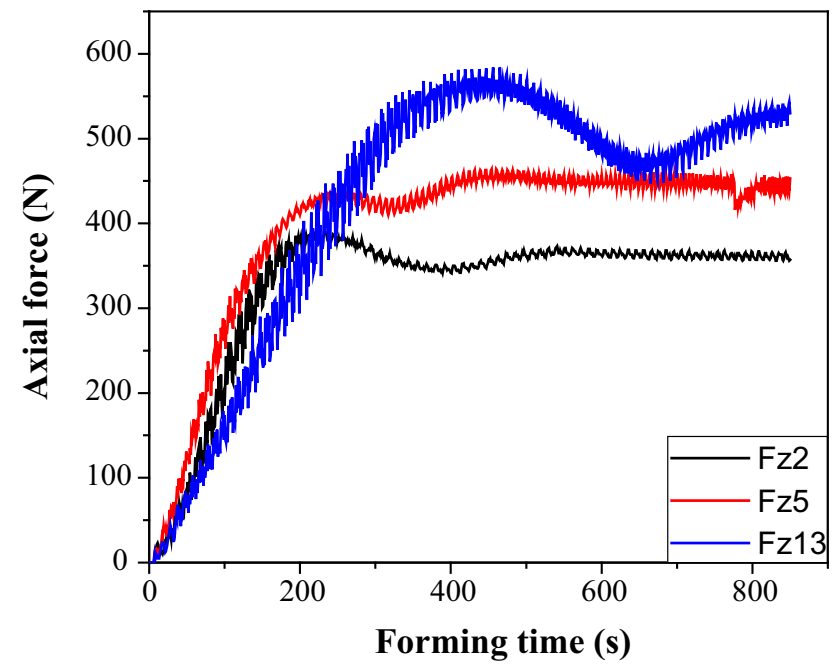

Figure 9. Force trend (polynomial) with severe parameters.

forces. The trend of wall angle is very interesting; forming forces are found to increase as wall angle is increased to $60^{\circ}$ from $50^{\circ}$ due to the fact that higher lateral area of punch tip touches the blank; therefore, the contact area at the tool-sheet interface is more for local deformation, which results in the increase in required forming forces. Later, maximum axial forces were observed to be decreased when wall angle was increased to $68^{\circ}$, which is very close to the limiting forming angle of the material. This decreasing trend of forces can be considered as an indicator of material failure. Moreover, sheet fracture was observed with $68^{\circ}$ wall angle specimens. A similar trend of forming forces was seen with the increase in feed rate, employing the fact that initially more material has to be pressed in a specific interval of time due to nature of deformation in the process. Hence, forming forces were found to be increased when feed rate was increased from level one to level two. Further increment in feed rate caused a reduction in maximum peak forces, which is certainly an effect of the increase in local ductility of material at the tool-sheet interface due to rise in temperature. Forming forces were found to be decreased with the increase in the side radius of the tool-tip. This fall is due to decrease in the contact surface of the tool and blank with the increase of side radius, and hence less material is available for deformation, requiring reduced forming forces. This is also in accordance with results obtained from preliminary experiments (figure 5).

The viscosity of forming oil has shown negligible effects on forming forces. Spindle speed of forming tool is one of the critical process factors. As we go for $1000 \mathrm{rpm}$ from 'free to rotate' condition through $500 \mathrm{rpm}$, forming forces are observed to be decreased. When the tool is left free to rotate, friction between tool and sheet in contact zone is reduced significantly, and hence required forming forces increase. Formability of the material increases considerably at higher spindle speeds during the SPIF process due to increase in temperature, which is the result of the increase in friction between the punch and sheet material, and reduced forming forces are required for local deformation of the work-piece. 


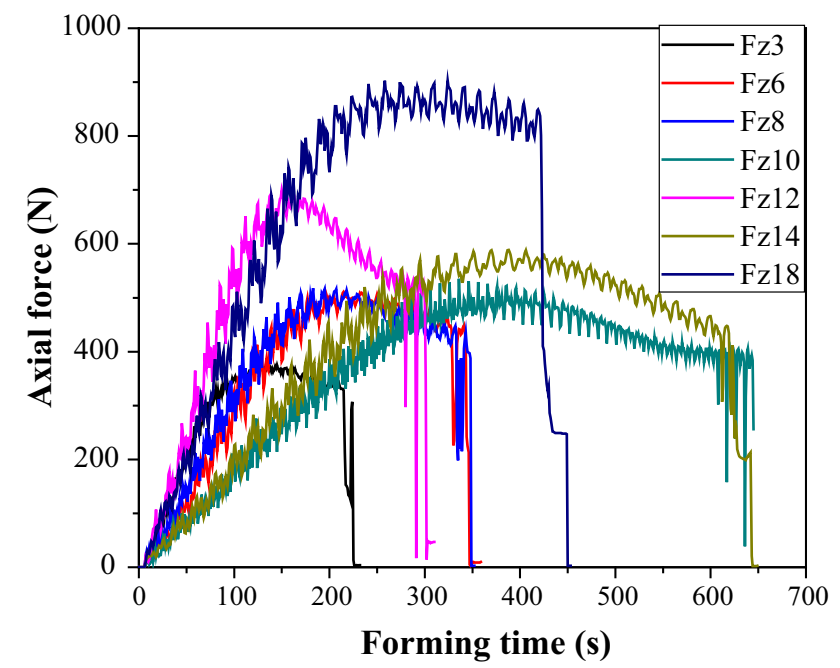

Figure 10. Force trend (monotonic decrease) with critical parameters.

Spindle speed can be utilized as an important factor to employ a wide range of materials: highly ductile materials to
The estimated average value of axial peak forming forces is determined as

$$
\begin{aligned}
\mu_{\mathrm{FF}}= & \{(A 1+B 1+C 1+D 1+E 1+F 3+H)-(6 \mu)\} \\
= & 445.3+502.3+463.3+542.3+532.4+518.3 \\
& +526.0-(6 \times 567.57)=124.48 \mathrm{~N},
\end{aligned}
$$

where values of $A 1, B 1, C 1, D 1, E 1, F 3$ and $H 3$ are taken from table 8 . The $95 \%$ confidence intervals of confirmation experiments $\left(\mathrm{CI}_{\mathrm{CE}}\right)$ are calculated using Eqs. (2) [21] and (3) as follows:

$$
\mathrm{CI}_{\mathrm{CE}}=\sqrt{f \alpha(1, f e)\left(\frac{1}{\eta e f f}+\frac{1}{R}\right) V e}
$$

where $\mathrm{F} \alpha(1, \mathrm{fe})$ is the $F$-ratio at a confidence level of $(1-\alpha)$ against DOF 1 . For this case, fe $=38$; hence, $\mathrm{F} \alpha(1,38)=$ 4.10 (from the design and analysis table) [21].

$\mathrm{Ve}=$ variance of error for forming force $=134$ (from the ANOVA table)

$$
\eta_{\text {eff }}=\frac{N}{1+\text { total degrees of freedom involved in prediction of mean }}
$$

materials having low ductility. Moreover, heat generation at the tool-sheet interface can be controlled by tool rotation, which is able to reduce forming forces and is important for safe uses of forming machinery.

\subsection{Prediction of optimal forming force model}

Response tables and response graphs suggest that better results for axial peak forces are observed when the selected input factors are varied at particular levels. These variables and levels are sheet thickness $A 1$, punch diameter $B 1$, vertical step size $C 1$, wall angle $D 1$, feed rate $E 1$, tool shape $F 3$, the viscosity of lubricant $G 1$ and tool rotation $H 3$. Only significant input factors have been considered to estimate the optimal value of forming forces with their confidence intervals. Confirmatory experiments have also been conducted and their results are validated with the estimated forming forces, which must lie within the $95 \%$ confidence intervals of optimal output, $\mathrm{CI}_{\mathrm{CE}}$.

For measured axial forming force, the total average of the population is $\mu=\left(\Sigma \mathrm{Fz}_{\mathrm{a}}+\Sigma \mathrm{Fz}_{\mathrm{b}}+\Sigma \mathrm{Fz}_{\mathrm{c}}\right) / 54=567.57 \mathrm{~N}$, where values of $\mathrm{Fz}_{\mathrm{a}}, \mathrm{Fz}_{\mathrm{b}}$ and $\mathrm{Fz}_{\mathrm{c}}$ are peak axial forces for trials 1-3 for the same combination of input parameters and taken from table 6 . where $N$ is the total number of experiments. Hence, $\eta_{\mathrm{eff}}=$ $(18 \times 3) /(1+15)=3.375 . R$ is the number of repetitions for each combination $=3$.

Now, putting these values in Eq. (3)

$$
\mathrm{CI}_{\mathrm{CE}}=\sqrt{ }(4.10(1 / 3.375+1 / 3) 134)=18.60 \mathrm{~N} \text {. }
$$

Hence, the confidence interval is $105.88 \leq \mu_{\mathrm{FF}} \leq 143.08$.

\subsection{Confirmation experiment}

Experiments for confirming the optimal values for peak forming forces have been performed at optimal levels of input parameters on AA2024-O sheets. Predicted results have been compared to the average values of confirmatory experiments. Each set of experiment has been performed thrice and then average values of forming forces have been obtained. It is clear from table 9 that average value of confirmatory results is within $95 \%$ of the confidence interval.

\subsection{Trends of axial forces}

Results obtained from experimental tests with the different combinations of parameters (table 6) permit analysis of 

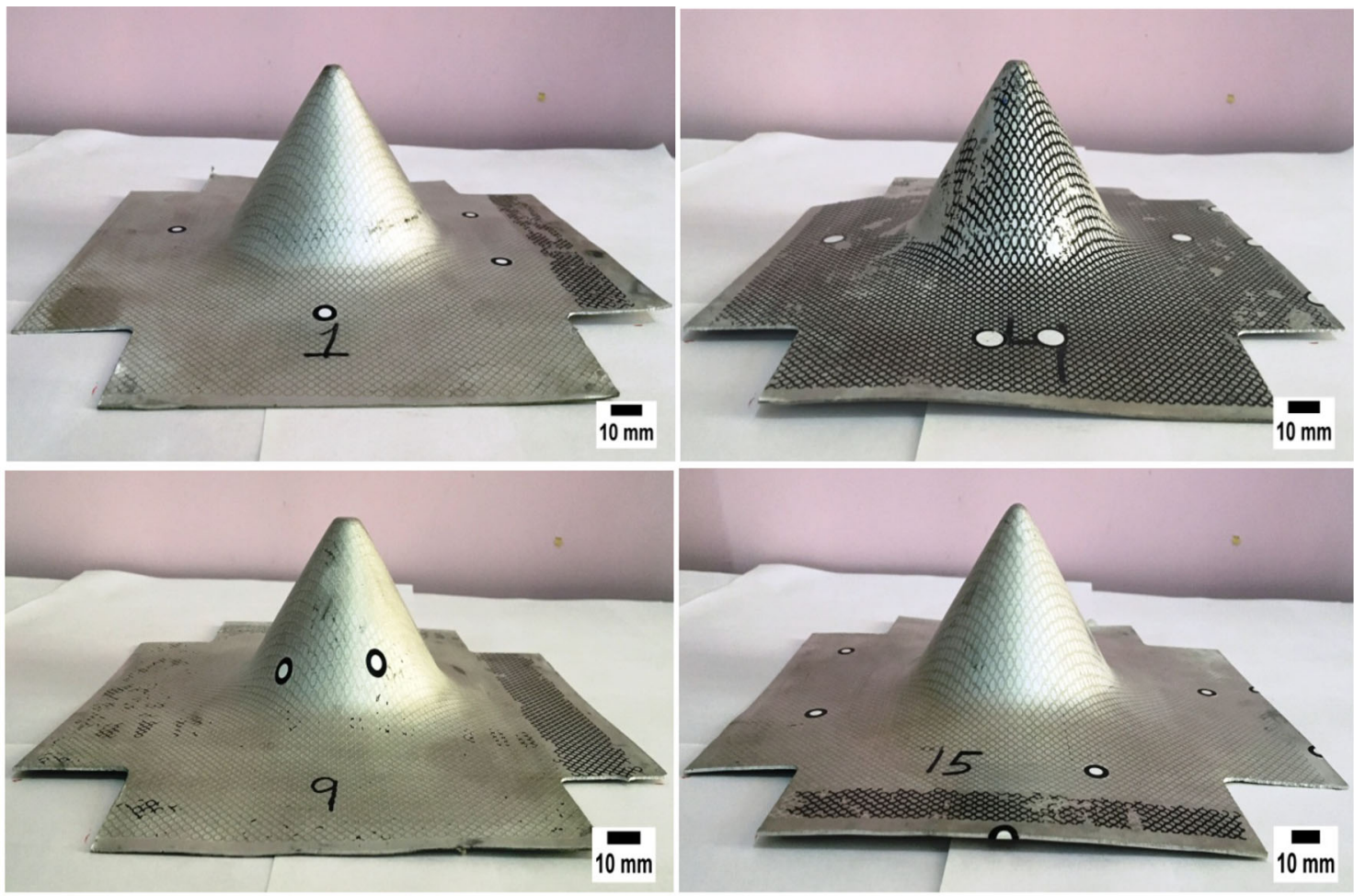

(a)
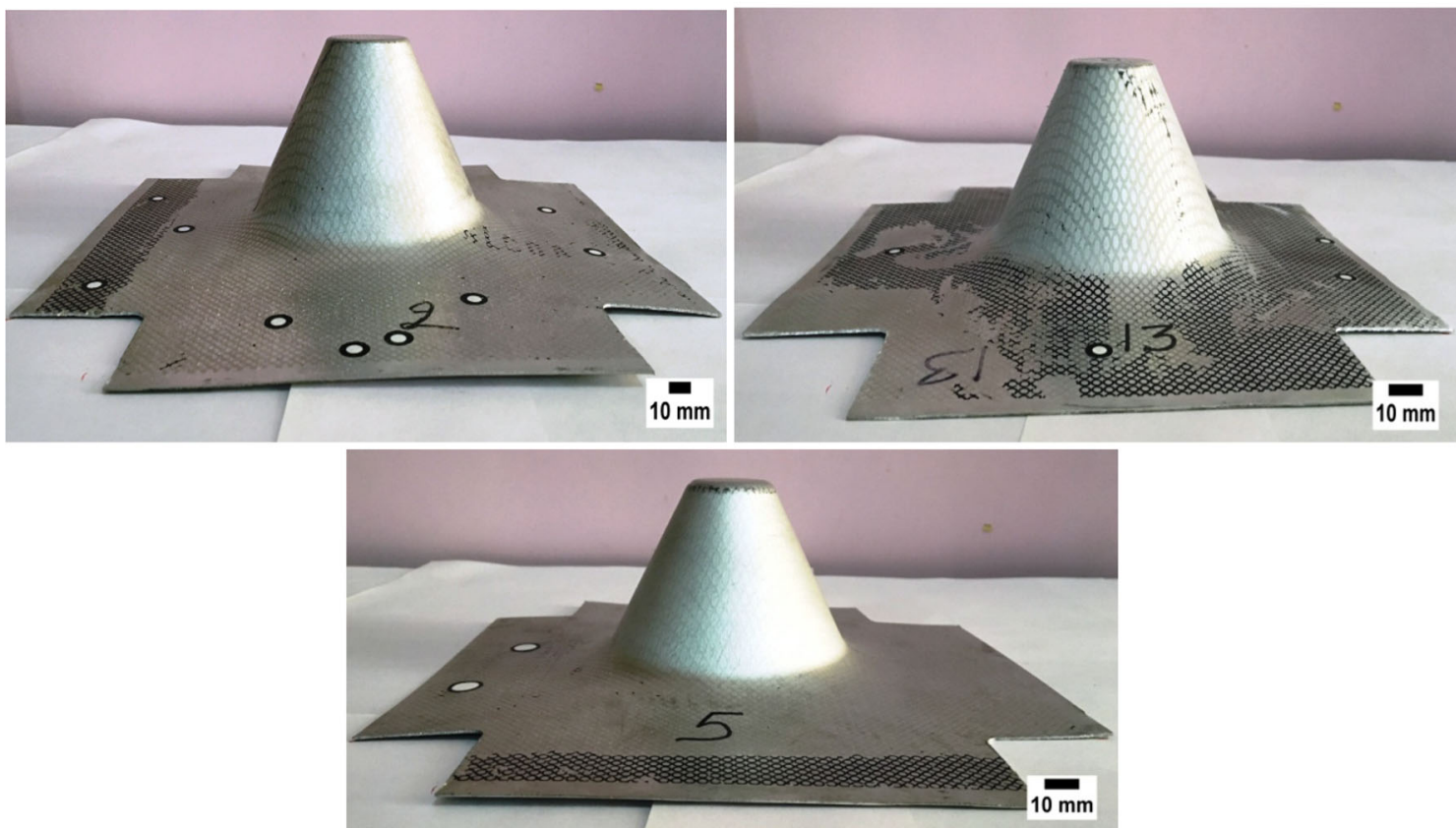

(b)

Figure 11. Successfully formed conical frustum for (a) wall angle $50^{\circ}$ and (b) wall angle $60^{\circ}$.

forming force trends after peak values. It is very interesting to show that up to a peak value of forces there is a gradual increase, which is obviously due to bending mechanics in the former part of the formed component. After reaching peak values, it is believed that stretching mechanics exists during the process and a very complex force trend is observed, which is certainly due to two different effects produced in material, which are work hardening (results in 


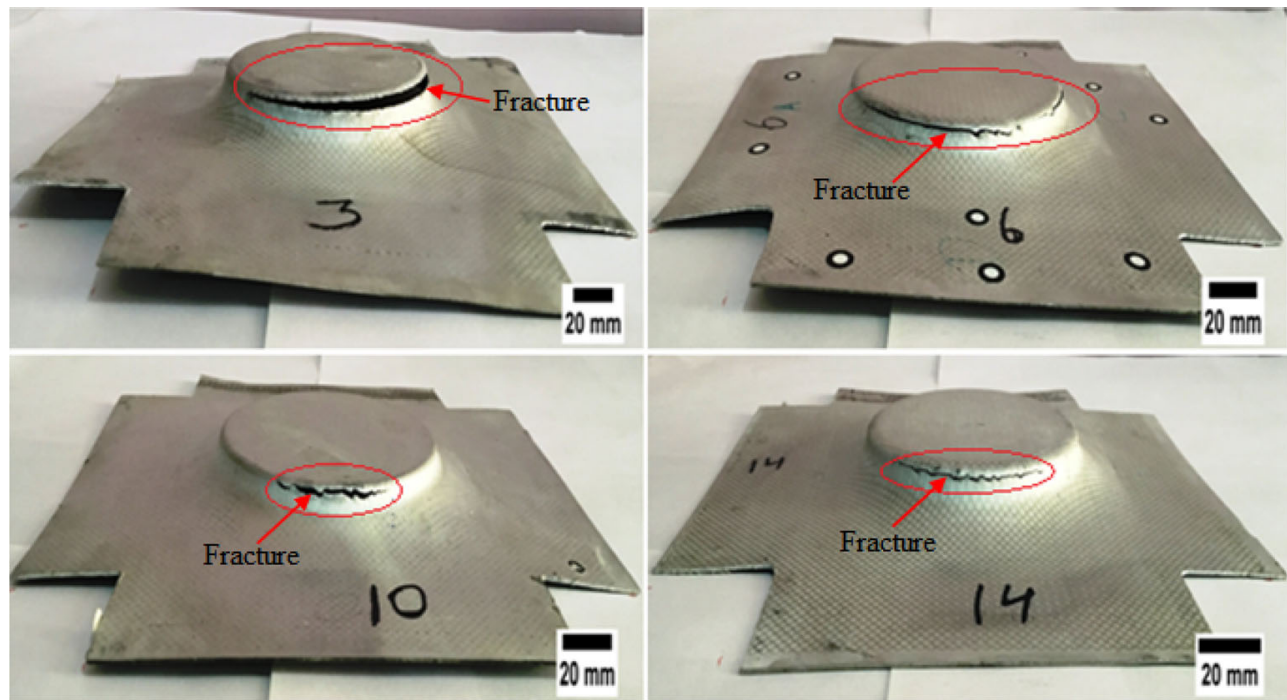

(a)

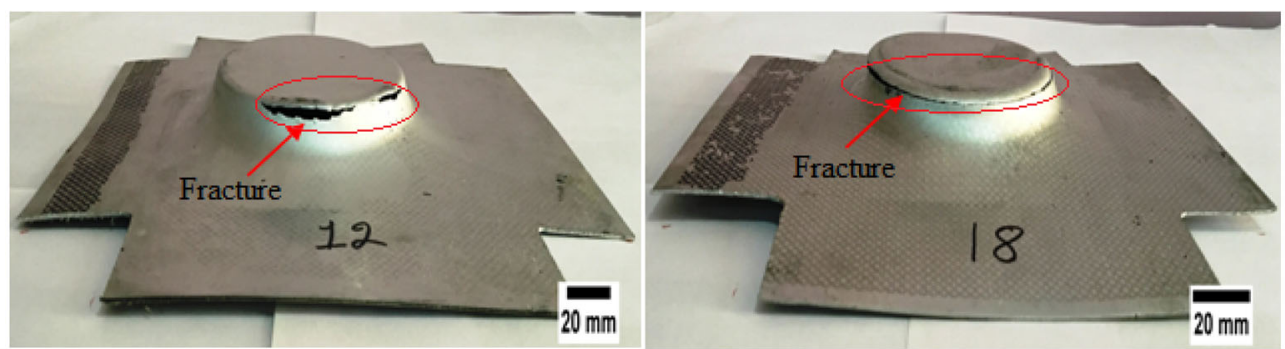

(b)

Figure 12. Fractured conical frustum for (a) wall angle $68^{\circ}$ and (b) wall angle $60^{\circ}$.

rising of forces) and sheet thinning (contrarily, tends to reduce forces). Three different observed trends after peak forces are

1. steady (figure 8),

2. polynomial (figure 9) and

3. monotonic decrease (figure 10).

Figures 8-10 present axial forming forces (Fz) in vertically downward direction with forming time. Fz1, Fz2, Fz3 and so on are the axial force components for experiment number 1, 2, 3 and so on, respectively (table 6). It is clear from figure 8 that for a low value of wall angle $\left(50^{\circ}\right)$, forming forces becomes steady after reaching peak values and a kind of dynamic equilibrium is achieved because of the drop in forming force due to material thinning and increase in force due to strain hardening. This trend for axial forces with low wall angle remains independent of other parameters used like step size, tool diameter, spindle speed, etc. and parts have been formed successfully without fracture and shown in figure 11a. The polynomial trend (figure 9) of forming forces has been observed for severe $\left(60^{\circ}\right.$ in this case) but not critical wall angle and a negative gradient occurs right after the force peak, which can be an influence of high thinning in starting of stretching and hence forming forces drop. Metal removal also occurs at this stage due to several moments of the tool in the same surface of the sheet (especially for lower step size). After this stage, force trend becomes steady, which is an effect of equilibrium between work hardening and blank thinning. Parts have also been formed without fracture and shown in figure $11 \mathrm{~b}$.

For a high value of wall angle ( $68^{\circ}$ in this study), the process yields to fracture and material hardening is not able to compensate the influence of sheet thinning, resulting in instability of the process; therefore, monotonically decreasing trend (figure 10) of forming forces has been observed and force suddenly decreases till sheet fracture (figure 12a). According to described conditions, a type of threshold between stable and unstable conditions was detected and force gradient after peak values can become a crucial indicator for the considered process for a different set of input factors. It is clear that the process is safe and stable when a safe set of parameters is employed (at low wall angles); otherwise, the process fails due to excessive thinning (at large step size and wall angle). Moreover, trend of force with severe wall angle value $\left(60^{\circ}\right)$ shifts from polynomial to 'monotonic decrease' trend, which has been observed with critical wall angle value, when step size is 
increased to $0.8 \mathrm{~mm}$ and failure of the sheet occurs (figure 12b), and shown in figure 10, where Fz12 and Fz18 curves represent $60^{\circ}$ wall angle and $0.8 \mathrm{~mm}$ step size. This is also in accordance with preliminary results where components were formed without fracture (figure 5) with severe parameters $\left(60^{\circ}\right.$ wall angle and $0.5 \mathrm{~mm}$ step size $)$. Hence, the gradient of force curve after peaks can be considered and utilized as a hidden variable for modifying process parameters by continuous comparison of crucial value and instant value for safe utilization of forming operation.

\section{Conclusion}

Primarily, effects of input factors on axial peak forming forces to form conical parts have been experimentally studied on AA6063-O aluminium sheets. Later, process parameters have been investigated and optimized using Taguchi approach for forming forces on AA2024-O sheets, which is an aerospace material. Primarily, results showed that lower peak forces were observed on AA6063-O aluminium sheets in trial 3 when a hemisphere-shaped tool of diameter $7.52 \mathrm{~mm}$ was employed with Alpha SP 68 forming oil at $1000 \mathrm{rpm}$ tool rotation, whereas maximum peak forces were observed in trial 11 when a flat end tool with lower corner radius (Flatend\#1) of diameter $15.66 \mathrm{~mm}$ was employed with Alpha SP 68 forming oil at $1000 \mathrm{rpm}$ spindle speed. When the tool shape is changed to hemispherical tip from the flat end tip, a decrease in the forming forces is observed, which is in accordance as contact surface of the tool and blank decreases with the increase of side radius, and hence less material is available for deformation, requiring reduced forming forces. The viscosity of forming oil does not influence forces significantly. The following conclusions were made when optimization of input factors was performed using Taguchi method:

- The forming force was found to increase with the increase in sheet thickness, tool diameter, and step size, whereas it was found to decrease with increase in spindle speed and side radius of the tool-tip. Increase in wall angle resulted in increasing forming force up to a limit $\left(60^{\circ}\right)$; later, force peak decreases with further increase in wall angle, which also becomes the limiting factor and an indicator of material failure due to excessive thinning of sheet metal.

- Experimental results showed that a punch diameter of $7.52 \mathrm{~mm}$ of hemispherical shape, step size of $0.2 \mathrm{~mm}$, wall angle of $50^{\circ}$, sheet thickness of $0.8 \mathrm{~mm}$, feed rate of $1000 \mathrm{~mm} / \mathrm{min}$, lubricating oil viscosity of $68 \mathrm{cSt}$ and spindle speed of $1000 \mathrm{rpm}$ result in optimum parametric condition on AA 2024-O alloy sheets using TM.

- According to ANOVA statistical analysis, the most dominant input parameter is sheet thickness with a contribution of $50.17 \%$ followed by step size (23.28\%), tool diameter (10.51\%), tool shape
$(6.04 \%)$, spindle speed $(5.84 \%)$, feed rate $(2.28 \%)$, wall angle (1.53\%) and viscosity of forming oil (0.04\%).

- Confirmation tests that were conducted on optimum levels of input factors showed that axial peak forces were within the confidence interval at $95 \%$ confidence level and close to predicted results. The estimated optimal values for forming force were $124.48 \mathrm{~N}$, whereas, confidence intervals were $105.88 \leq \mu_{\mathrm{FF}} \leq$ 143. The proposed model efficiently predicted the forming forces of formed components.

Moreover, forces gradually increase up to peak values due to bending mechanics till a limited forming depth; later, stretching mechanics exists and force trends vary due to sheet thinning and strain hardening, and depend upon instant input factors that can be categorized as a safe, severe and crucial set of parameters. Hence, the gradient of force curve after peaks can be considered and utilized as a hidden variable for modifying process parameters by continuous comparison of crucial value and instant value for safe utilization of forming operation. Therefore, SPIF suitability can be enhanced on the industrial scale with the given guidelines regarding a relation between input parameters and required forming forces. Analysis of formability and geometrical accuracy of the formed components would be focused in the future work.

\section{Acknowledgement}

The authors have no conflict of interest. The authors would like to thank ARK Mould \& Tools Ltd., Gurgaon, and Nictech, Jaipur, for their assistance. The authors would also like to thank Mr Udayveer Singh, Mr Bissan Singh and Er. Sumit Nagar for their appreciable contribution in developing the experimental set-up.

\section{References}

[1] Kim Y H and Park J J 2002 Effect of process parameters on formability in incremental forming of sheet metal. J. Mater. Process. Technol. 130: 42-46

[2] Li P, He J, Liu Q, Yang M, Wang Q, Yuan Q and Li Y 2017 Evaluation of forming forces in ultrasonic incremental sheet metal forming. Aerosp. Sci. Technol. 63: 132-139

[3] Wu S H, Reis A, Andrade Pires F M, Santos A D and Barata da Rocha A 2012 Study of tool trajectory in incremental forming. Adv. Mater. Res. 472: 1586-1591

[4] Ham M and Jeswiet J 2006 Single point incremental forming and the forming criteria for AA3003. CIRP Ann. Manuf. Technol. 55(1): 241-244

[5] Bagudanch I, Centeno G, Vallellano C and Garcia-Romeu M L 2013 Forming force in Single Point Incremental Forming under different bending conditions. Procedia Eng. 63: 354-360 
[6] Blaga A and Oleksik V 2013 A study on the influence of the forming strategy on the main strains, thickness reduction, and forces in a single point incremental forming process. $A d v$. Mater. Sci. Eng., Article ID 382635

[7] Thibaud S, Hmida R B, Richard F and Malécot P 2012 A fully parametric toolbox for the simulation of single point incremental sheet forming process: numerical feasibility and experimental validation. Simul. Model. Pract. Theory 29: $32-43$

[8] Arfa H, Bahloul R and BelHadjSalah H 2013 Finite element modelling and experimental investigation of single point incremental forming process of aluminum sheets: influence of process parameters on punch force monitoring and on mechanical and geometrical quality of parts. Int. J. Mater. Form. 6(4): 483-510

[9] Li Y, Liu Z, Daniel W J T and Meehan P A 2014 Simulation and experimental observations of effect of different contact interfaces on the incremental sheet forming process. Mater. Manuf. Process. 29(2): 121-128

[10] Bagudanch I, Garcia-Romeu M L, Centeno G, Elías-Zúñiga A and Ciurana J 2015 Forming force and temperature effects on single point incremental forming of polyvinylchloride. $J$. Mater. Process. Technol. 219: 221-229

[11] Petek A, Kuzman K and Kopac J 2009 Deformations and forces analysis of single point incremental sheet metal forming. Arch. Mater. Sci. Eng. 35(2): 107-116

[12] Duflou J R, Szekeres A and Vanherck P 2005 Force measurements for single point incremental forming: an experimental study. Adv. Mater. Res. 6: 441-448

[13] Centeno G, Bagudanch I, Martínez-Donaire A J, GarciaRomeu M L and Vallellano C 2014 Critical analysis of necking and fracture limit strains and forming forces in single-point incremental forming. Mater. Des. 63: 20-29
[14] Liu Z, Li Y and Meehan P A 2013 Experimental investigation of mechanical properties, formability and force measurement for AA7075-O aluminum alloy sheets formed by incremental forming. Int. J. Precis. Eng. Manuf. 14(11): 1891-1899

[15] Azevedo N G, Farias J S, Bastos R P, Teixeira P, Davim J P and de Sousa R J A 2015 Lubrication aspects during single point incremental forming for steel and aluminum materials. Int. J. Precis. Eng. Manuf. 16(3): 589-595

[16] Ambrogio G, Filice L and Micari F 2006 A force measuring based strategy for failure prevention in incremental forming. J. Mater. Process Technol. 177(1-3): 413-416

[17] Filice L, Ambrogio G and Micari F 2006 On-line control of single point incremental forming operations through punch force monitoring. CIRP Ann. Manuf. Technol. 55(1): 245-248

[18] Singer M and Liewald M 2014 Effect of surface enlargement and of viscosity of lubricants on friction behaviour of advanced high strength steel material during deep drawing. Adv. Mater. Res. 1018: 253-260

[19] Peters M and Leyens C 2009 Aerospace and space materials. Mater. Sci. Eng. 3: 1-11

[20] Liao H C 2006 Multi-response optimization using weighted principal component. Int. J. Adv. Manuf. Technol. 27(7-8): $720-725$

[21] Ross P J 2005 Taguchi techniques for quality engineering. New Delhi: Tata McGraw-Hill Publishing Company Limited

[22] Goswami A and Kumar J 2014 Investigation of surface integrity, material removal rate and wire wear ratio for WEDM of Nimonic 80A alloy using GRA and Taguchi method. Eng. Sci. Technol. Int. J. 17(4): 173-184

[23] Jeswiet J, Micari F, Hirt G, Bramley A, Duflou J and Allwood J 2005 Asymmetric single point incremental forming of sheet metal. CIRP Ann. Manuf. Technol. 54(2): 88-114 